\title{
Composição gravimétrica dos resíduos sólidos urbanos na cidade de Nova Ponte (MG)
}

\section{Gravimetric composition of urban solid waste in the city of Nova Ponte (MG)}

Data de entrada: 29/07/2014

Data de aprovação: $13 / 07 / 2015$

\section{Resumo}

Com a crescente urbanização aliada ao consumo exagerado tem como consequência a geração em grandes quantidades de resíduos sólidos. Para se obter informações da viabilidade da implementação de usinas de triagem de resíduos sólidos, pátios de compostagem, o dimensionamento de aterros sanitários e ainda prever lucros com venda destes resíduos torna-se necessário e indispensável conhecer em quantidade, volume e densidade os resíduos sólidos gerados sejam eles em empresas ou ainda em municípios de pequeno, médio ou grande porte. $O$ objetivo desse estudo foi caracterizar e avaliar a geração dos resíduos sólidos urbanos (RSU) produzidos pela população urbana da cidade de Nova Ponte - MG. Para obtenção desses dados foram realizada coleta de amostras em todos os bairros da cidade onde após a coleta, estes foram pesados, separados e classificados como vidros, plásticos, metais, papel, papelão, Pet, alumínio, matéria orgânica e rejeito. A geração per capita de resíduos sólidos em Nova Ponte - MG foi de 0,554 kg/hab./dia. Do total de resíduos gerados 39,6\% podem e devem ser reintegrados ambientalmente, socialmente e economicamente sendo necessária por parte do município a implantação de um programa de reciclagem tanto dos resíduos potencialmente recicláveis quanto da matéria orgânica gerada, aliada a um programa de educação ambiental com as populações do município a fim de contribuir com a separação dos resíduos, principalmente dos recicláveis dos não recicláveis.

Palavras-chave: gravimetria, reciclagem, balanço de massa

\section{Abstract}

The growing urbanization, together with excessive consumption, result in a big generation of solid residues. To obtain information of the feasibility of implementing solid residues sorting, composting courtyards, the landfills proportions as much as the foresight of the profits earned with these residues selling become essential to know the quantity, volume and density of generated solid residues whether in companies or municipalities of small,

Hygor Evangelista Siqueira - Tecnólogo em Gestão Ambiental. Especialista em Saneamento Ambiental. Pós-graduando em Gestão Ambiental pelo Instituto Federal de Educação, Ciência e Tecnologia do Triângulo Mineiro - Campus Uberaba. E-mail: hygorsiqueiraayahoo.com.br. Amilton Diniz e Souza - Biólogo. Doutor em Saneamento, Meio Ambiente e Recursos. Professor do Instituto Federal de Educação, Ciência e Tecnologia do Triângulo Mineiro - Campus Uberaba. E-mail: amiltonaiftm.edu.br.

Antônio Carlos Barreto - Engenheiro agrícola. Doutor em Engenharia Agrícola. Professor titular do Instituto Federal de Educação, Ciência e Tecnologia do Triângulo Mineiro - Campus Uberaba. E-mail: barretoaiftm.edu.br.

Vera Lúcia Abdala - Geógrafa. Doutora em Agronomia. Professora titular do Instituto Federal de Educação, Ciência e Tecnologia do Triângulo Mineiro - Campus Uberaba. E-mail: vlabdalaaiftm.edu.br. 
medium or large size. The purpose of this study was to characterize the urban solid residues (USR) gravimetric composition, produced by the population of the city of Nova Ponte - MG. To obtain the data, samples from all neighborhood of the city were collected, weighted, separated and classified as glass, plastic, metals, paper, PET, aluminum, organic material and wastes. The per capita production of solid residues in Nova Ponte was $0.555 \mathrm{~kg} /$ hab./day. About 39.6\% of produced residues may and must be reintegrated environmentally, socially and economically. Being the implementation of a recycle program, for residues potentially recyclable and produced organic materials, necessary for the city administration, allied to an environment education program aimed to the population that may contribute with the separation of recyclable and non-recyclable residues.

Keywords: gravimetric, recycling, mass balance

\section{INTRODUÇÃO}

Uma das maiores preocupações que acompanha a humanidade no decorrer dos anos é a crescente geração de resíduos sólidos pela população, os quais são destinados ao ambiente. Esses resíduos em contato com o ambiente de maneira inadequada podem trazer transtornos à sociedade e contaminação do solo, água e ar.

As atividades humanas sejam elas de qualquer natureza sempre resultará em geração de diferentes tipos de resíduos. $O$ constante crescimento das populações urbanas, o avanço da industrialização, a melhoria no poder aquisitivo, vêm potencializando a acelerada geração de grandes volumes de resíduos sólidos (RIBEIRO, 2007).

O "lixo" na linguagem técnica denomina-se como resíduos sólidos possuem vários fatores que contribuem para sua geração, entre elas o crescimento gradativo e desordenado da população, a aceleração do processo de ocupação do território urbano e do aumento dos bens de consumo descartáveis, popularizados pelo aumento da produção industrial. Esses fatores têm levado o homem a produzir grandes quantidades de resíduos sólidos, muitas vezes sem políticas efetivas que contemplem um gerenciamento adequado na sua destinação final (SISINNO, 1996).

Conforme a Política Nacional de Resíduos Sólida instituída pela Lei Federal no. 12.305/2010 os Resíduos Sólidos Urbanos - RSU são compostos por resíduos domiciliares, que se originam de atividades domésticas em residências urbanas; e resíduos de limpeza urbana, sendo estes compostos por resíduos de varrição, limpeza de logradouros e vias públicas e outros serviços de limpeza pública. Têm se ainda classificados como RSU os classificados como Comercial que se originam de atividades comercias e que dependendo da geração diária de um determinado estabelecimento comercial sua destinação é de responsabilidade da prefeitura.

Segundo Bidone e Povinelli (1999), os resíduos sólidos urbanos apresentam grande diversidade e se originam das mais variadas atividades humanas e ambientes urbanos. Compõe essa infinidade de materiais reunidos, classificada como sem utilidade e desprezada: restos de frutas, legumes e alimentos em geral, plásticos e metais diversos, vidros, papéis, embalagens em geral, matérias provenientes de vias públicas, praças, jardins, materiais cerâmicos, ossos, couro, trapos, terra, pedra, material séptico ou contaminado (provenientes de serviços de saúde), animais mortos, restos de carros, restos mobiliários entre outros.

Do ponto de vista sanitário e ambiental, a adoção de soluções inadequadas para o problema do lixo faz com que os riscos de contaminação do solo, do ar e da água, a proliferação de vetores e de doenças se agravem; e do lado econômico, a produção exagerada do lixo e a disposição final sem critérios representam um desperdício de materiais e de energia. (BARROS e MOLLER, 1995). 
Cada sociedade gera um determinado tipo de resíduo sólido, uma mistura de materiais que varia em função de hábitos e costumes da população, do clima e da estação, e das atividades econômicas existentes no município e que mudam ao longo do tempo. Para tanto se torna indispensável à identificação periódica das características dos resíduos sólidos gerados pelo município, que é o estudo primordial para se caracterizar tanto sua quantidade quanto sua tipologia.

A Composição gravimétrica dos resíduos sólidos apresenta as porcentagens dos diferentes tipologias e características dos materiais constituintes dos RSU que são compostos por: papel, papelão, plástico rígido, plástico filme, metais ferrosos, metais não ferrosos, vidros, borrachas, madeira, couros, trapos, cerâmicas, ossos, madeiras, matéria orgânica. (PEREIRA NETO, 2007). Portanto, conforme Monteiro et al. (2001) e Pereira Neto (2007), a composição gravimétrica dos resíduos sólidos ou composição física expressa o percentual de cada componente presente nesses resíduos em relação ao peso total da amostra estudada.
O conhecimento da composição gravimétrica dos RSU é uma ferramenta primordial para tomadas de decisão quanto ao Planejamento e Gerenciamento dos Resíduos Sólidos, fazendo com que se conheça em números, os resíduos sólidos em um determinado local. É a partir dele que se têm informações concretas para o planejamento de aterros sanitária para determinados locais e ainda tomada de decisão quanto ao gerenciamento dos resíduos.

Este trabalho teve como objetivo o estudo da composição gravimétrica dos resíduos sólidos gerados no município de Nova Ponte - MG no ano de 2013.

\section{METODOLOGIA}

\subsection{Caracterização do Município}

O município de Nova Ponte está inserido na região do Alto Paranaíba, no estado de Minas Gerais, às margens do rio Araguari, localizada entre as coordenadas geográficas $19^{\circ} 11^{\prime} 54^{\prime \prime}$ (latitude sul) e $47^{\circ} 43^{\prime} 38$ " (longitude oeste) (Figura 1). Possui uma extensão territorial de $1.111,011 \mathrm{~km}^{2}$, sendo 8,997 $\mathrm{km}^{2}$ de área urbana e $1.102,014 \mathrm{~km}^{2}$ de área rural. Segundo o IBGE (2010) a população total do municí-

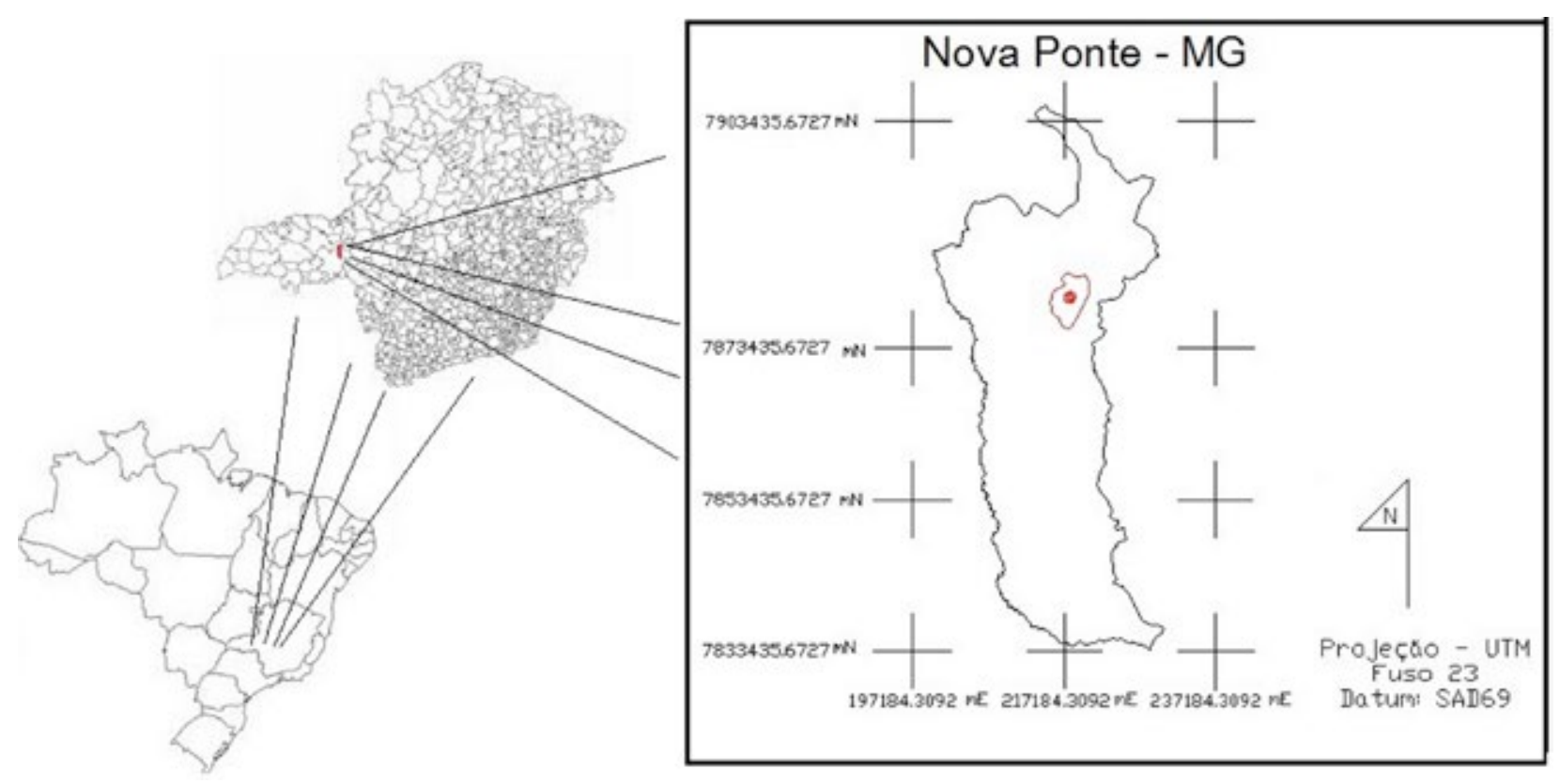

Figura 1 - Localização do município de Nova Ponte - MG 
pio de Nova Ponte corresponde a 12.812 habitantes sendo 10.991 habitantes inseridos na área urbana.

O município de Nova Ponte faz limites com as cidades de Indianópolis, Estrela do Sul, Romaria, Iraí de Minas, Uberaba, Sacramento, Santa Juliana e Pedrinópolis. Possui ainda em seu município comunidades como a de Almeida Campos, Jatobá, Lucas, Teixeira, Parque das Árvores. Destaca-se por estar às margens da Usina Hidrelétrica de Nova Ponte, que durante sua construção, teve sua cidade inundada, dando assim lugar a uma nova cidade planejada e com um grande atrativo turístico.

\subsection{Gerenciamento dos resíduos sólidos no município}

A coleta de resíduos sólidos urbanos (domésticos, públicos e comerciais) no município é de responsabilidade da própria prefeitura e se dá 3 (três) vezes por semana entre 08:00 as 17:00 horas, sendo realizado nas segundas-feiras, quartasfeiras e sextas-feiras, que, com a utilização de um caminhão compactador, segundo informações da prefeitura, são coletados aproximadamente 36 (trinta e seis) toneladas de resíduos sólidos semanalmente no município.

Os Resíduos de Serviço de Saúde - RSS (hospitalares) são coletados separadamente por empresa terceirizada e conveniada com a prefeitura, coletando ainda em farmácias e Unidades Básicas de Saúde inseridas no município, gerando no período de 15 dias aproximadamente $150 \mathrm{~kg}$ de RSS.

A coleta de resíduos na Zona Rural é realizada através de caçambas disponibilizadas em locais estratégicos e de acordo com a quantidade de resíduos sólidos gerados. Estão alocados no Trevo de acesso à comunidade de Almeida Campos, entrada da Comunidade do Jatobá, trevo de acesso ao Aeroporto, na comunidade do Brejão e na Comunidade Bom Jardim, sendo coletados quinzenalmente pela própria prefeitura.

\subsection{Materiais utilizados}

Para a realização deste estudo foi utilizado os seguintes equipamentos:

- 1 Balança eletrônica da marca Toledo com indicador digital e capacidade de medida de $300 \mathrm{Kg}$;

- Equipamentos de Proteção Individual (luvas, máscaras, botas);

- 1 Caminhão basculante (disponibilizado pela Prefeitura);

- 1 Trator com concha frontal (disponibilizado pela Prefeitura);

- 9 Coletores de plástico (Bombona);

- 1 Câmera Fotográfica Digital Sony de 14,1 megapixels;

- 2 cordas de 10 metros;

- 3 Vassourões;

- 2 pás;

- 9 folhas de Papel A4;

- Pincel;

- Calculadora.

\subsection{Etapas do processo do estudo gravimétrico}

- Definição da rotas e coleta de amostras dos resíduos sólidos urbanos;

- Pesagem, cálculo e medidas de volume e identificação dos recipientes (coletores) a serem depositados os resíduos;

- Pesagem e cálculo do volume do caminhão coletor com os resíduos amostrais;

- Transporte dos resíduos amostrais para o local onde será realizado o estudo gravimétrico;

- Descargas dos resíduos oriundos do equipamento sobre área disponível; 
- Pesagem do mesmo caminhão coletor das amostras de resíduos só que vazio;

- Homogeneização manual da pilha, resultante do descarregamento;

- Quarteamento e escolha do quartil a ser caracterizado;

- Remoção das demais partes deixando no pátio somente a amostra do quartil escolhido com os resíduos;

- As amostras foram segregadas por classe em recipientes (coletores), devidamente identificados por tipo de materiais, peso líquido e volume;

- As amostras segregadas em seguidas foram pesadas, anotadas os valores de peso, volume, data e hora do trabalho;
- Os materiais após analisado foram descartados.

\subsubsection{Definição das rotas para coleta de resíduos sólidos amostrais}

Para a realização do estudo gravimétrico foi utilizada como referência para amostragem dos resíduos a NBR 10007/2004 onde primeiramente realizou-se a escolha das ruas de todos os bairros da cidade (centro, áreas comerciais, áreas nobres e periferias). Neste estudo foi realizado o mapeamento por parte dos bairros e consistiu em traçado de rota entre as áreas que serviram de coleta de amostras conforme ilustra a Figura 2.

Foi coletado ainda conforme ilustra a Figura 3 amostras de resíduos no residencial Parque das Árvores onde a coleta de amostra se deu na segunda-feira dia 08/04/2013.

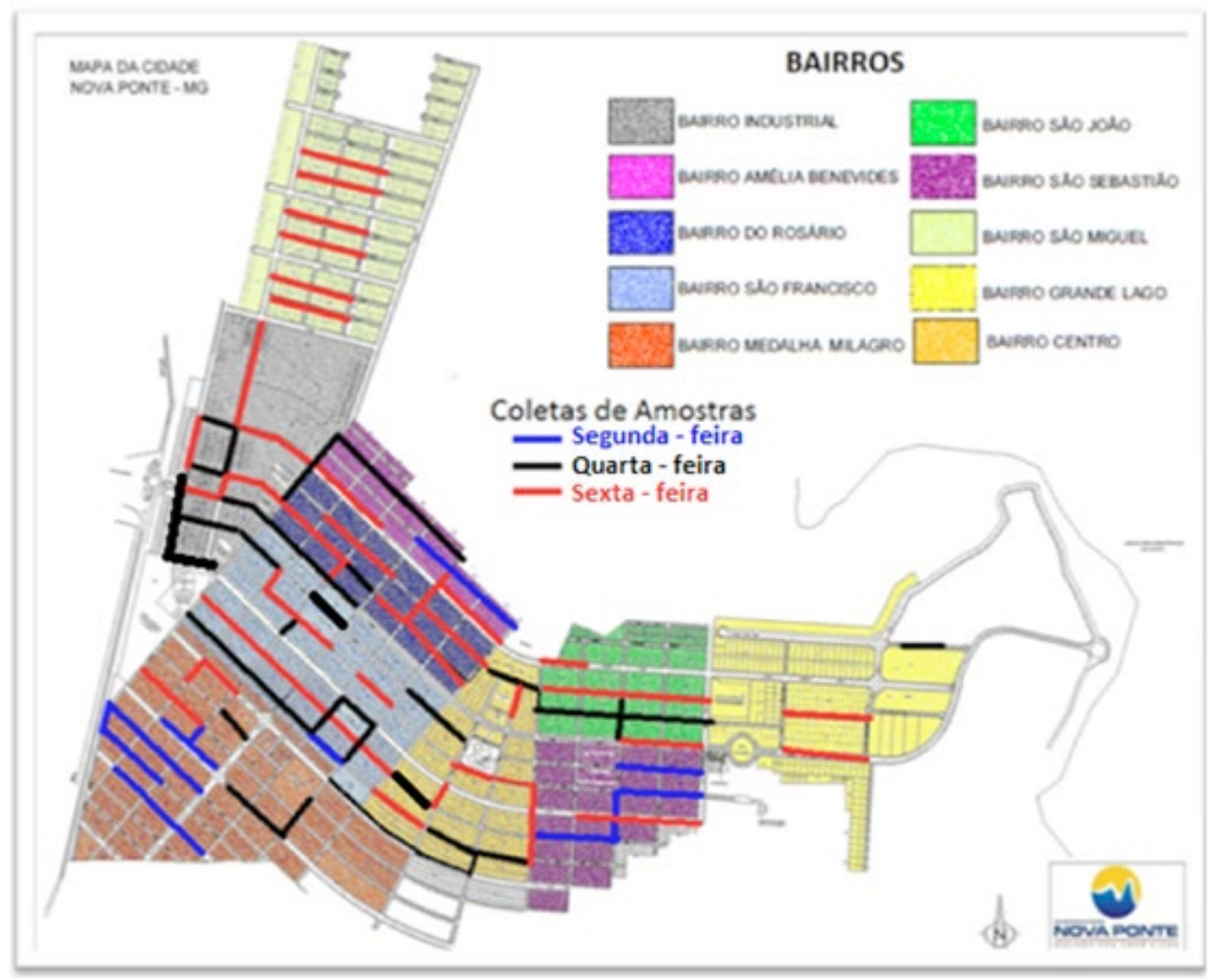

Figura 2 - Mapa das rotas de coleta de amostras em Nova Ponte - MG Fonte: Prefeitura Municipal de Nova Ponte (MODIFICADO) 


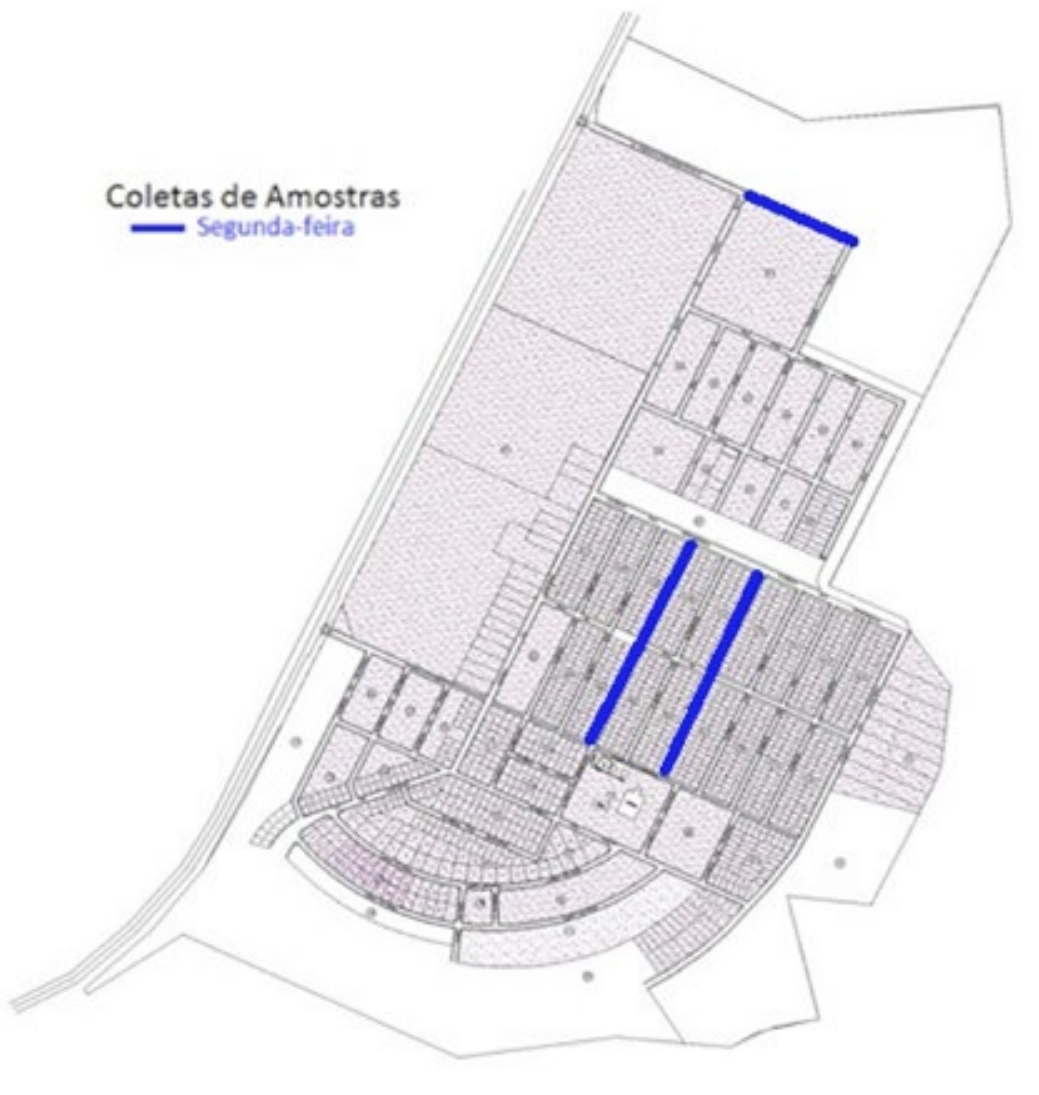

RESIDENCUL PAROUE DA ARVORES

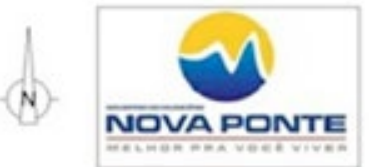

Figura 3 - Mapa das rotas no residencial das Árvores, Nova Ponte - MG Fonte: Prefeitura Municipal de Nova Ponte (MODIFICADO)

Definido os locais de coleta dos resíduos sólidos para servirem de amostragem, iniciou-se a coleta dos resíduos sólidos urbanos que foi realizada na segunda, quarta e sexta-feira $(08,10$ e 12/04/2013) totalizando 3 (três) coletas durante 1 (uma) semana.

Para a coleta especial de amostragem para o estudo foi utilizado um caminhão basculante (sem compactador) da própria prefeitura e 5 (cinco) servidores municipais que atuam na limpeza urbana do município.

Para esse tipo de estudo é de suma importância que os resíduos sólidos urbanos não sejam compactados, pois caso contrário, reduzem o volume de alguns materiais interferindo assim nos resultados do estudo gravimétrico. 


\subsubsection{Quarteamento dos Resíduos Sólidos}

Realizado a coleta das amostras se deu então o processo de segregação e separação dos resíduos sólidos.

Em um galpão coberto disponibilizado pela prefeitura de Nova Ponte com o auxilio dos funcionários que atuam na limpeza urbana do município foi despejado os resíduos coletados em um formato de círculo e o mais uniformemente possível para após realizar o quarteamento.

$\mathrm{Na}$ figura 4 pode-se observar que os resíduos não estão compactados o que dá ainda mais exatidão na caracterização gravimétrica uma vez que, as compactações alteram a densidade de alguns materiais e consequentemente interferem o balanço de massa/volume.

O quarteamento (Figura 5) se deu com a utilização de duas cordas as quais foram cruzadas na superfície dos resíduos já despejados e no formato de um quadrado, obtendo-se assim a orientação dos limites onde serão divididos os resíduos em quatro partes. Foi efetuada assim a escolha do quartil o qual será a amostra a ser utilizada.

Conforme ilustra a figura anterior, na separação do quartil utilizou-se os cruzamentos das cordas como o limite de divisão do mesmo. Para que não houvesse uma mistura entre os limites estabelecidos pela divisão, foi realizada uma separação em formato de corte nos limites da corda protegendo assim para que não houvesse uma mistura de resíduos com os quartiis ao lado (Figura 6).

Separado a amostra de interesse a qual realizou-se a caracterização gravimétrica foi necessária a remoção dos outros resíduos. Para isso utilizou-se um trator com concha frontal e ainda contou-se com o auxilio dos funcionários da Prefeitura de Nova Ponte, deixando assim na área, somente os resíduos separados para a caracterização gravimétrica.

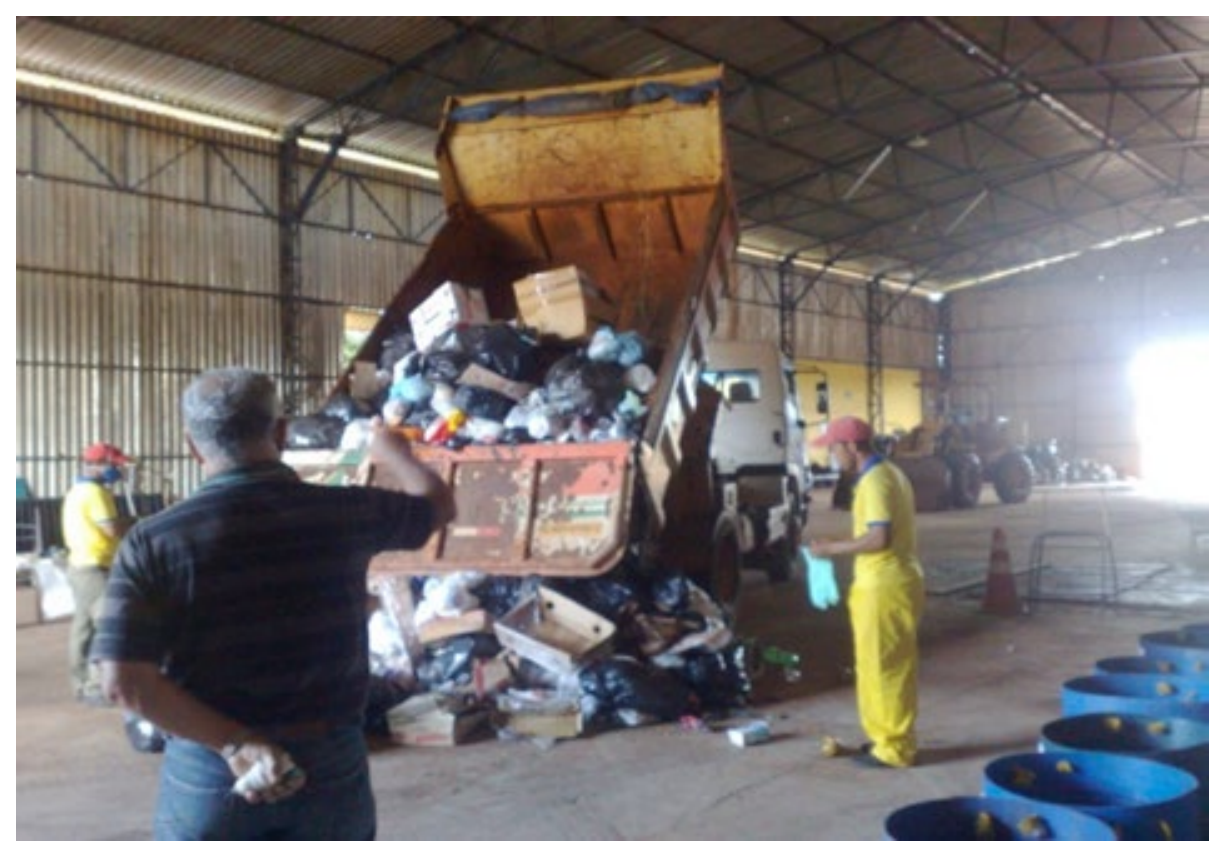

Figura 4 - Despejo dos resíduos sólidos Crédito da Imagem: Hygor Evangelista Siqueira 


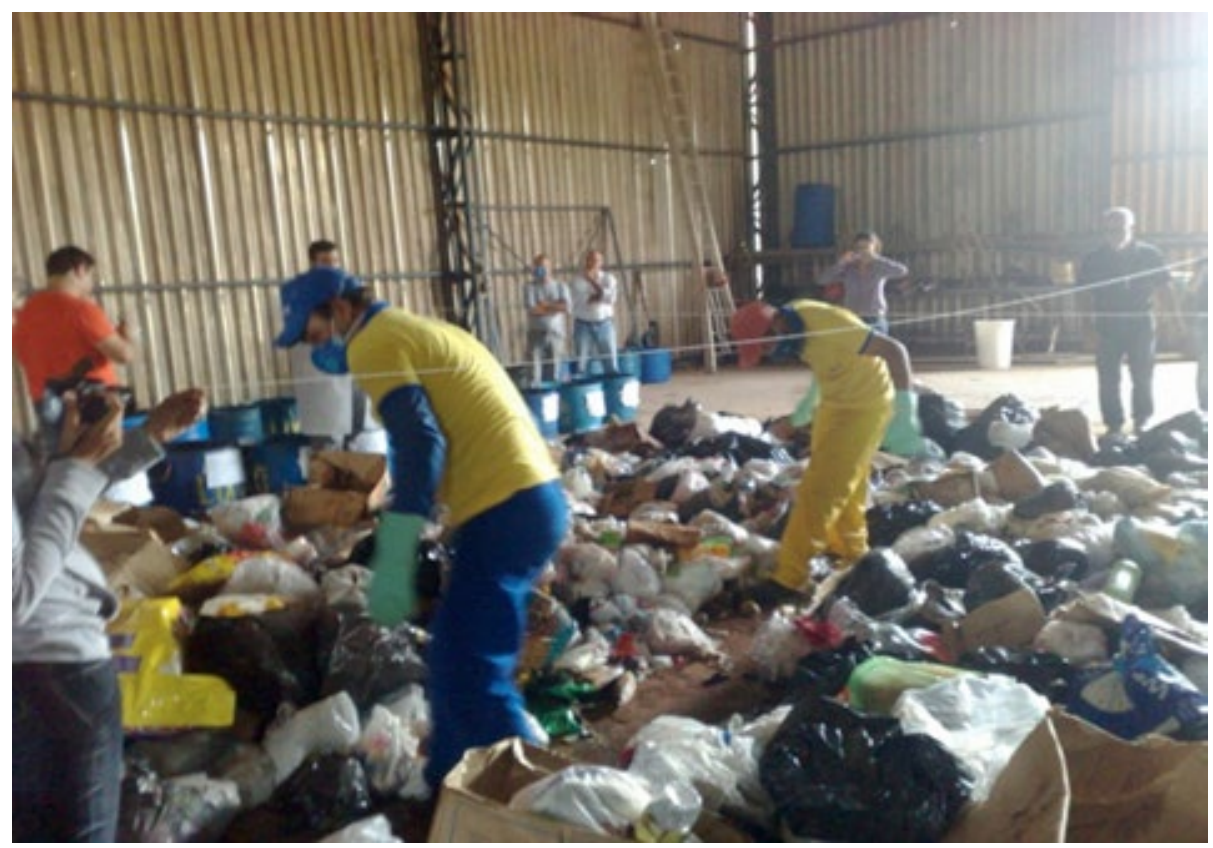

Figura 5 - Quarteamento dos resíduos sólidos Crédito da Imagem: Hygor Evangelista Siqueira

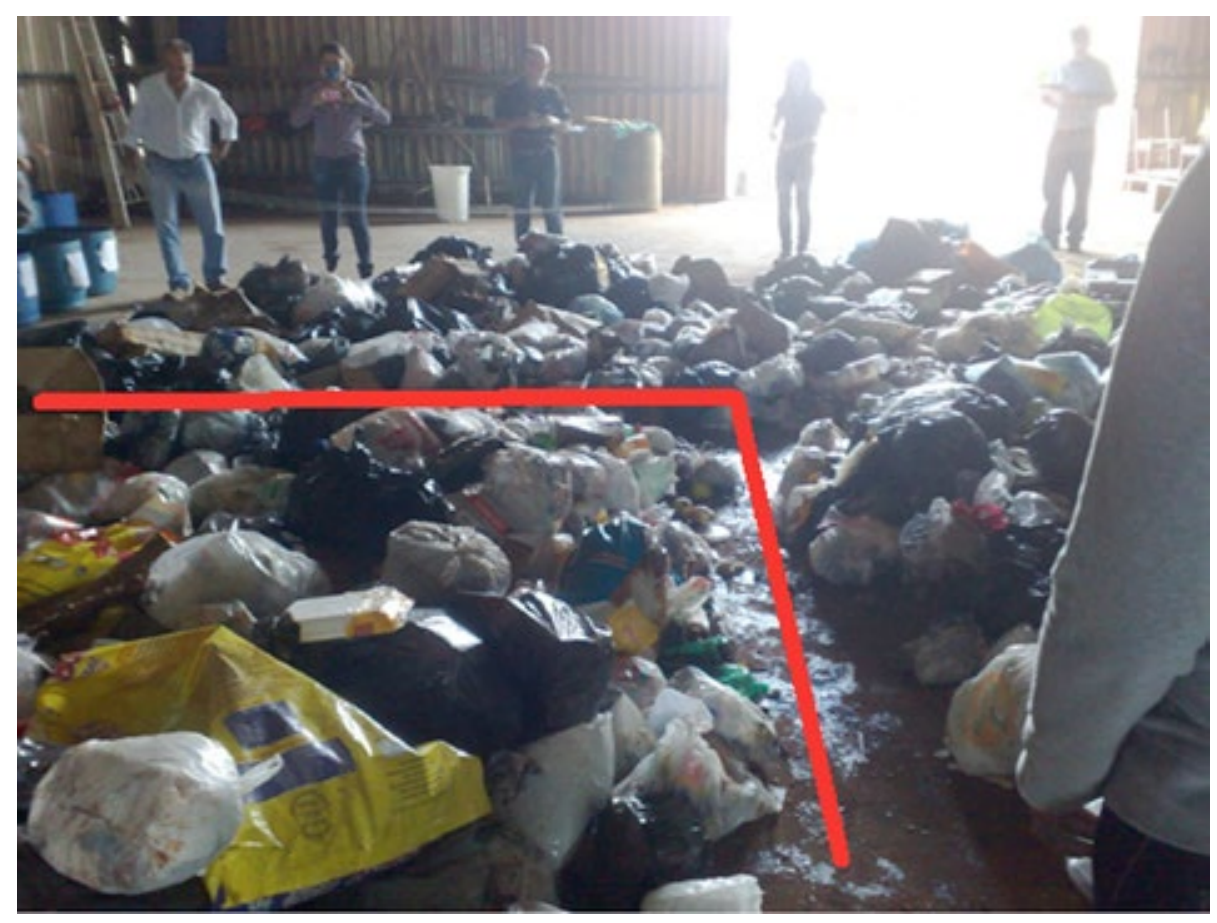

Figura 6 - Separação do quartil a ser utilizado na caracterização Crédito da Imagem: Hygor Evangelista Siqueira 


\subsubsection{Composição Gravimétrica dos Resíduos Sólidos}

Para a composição gravimétrica dos resíduos sólidos foi necessário a utilização de tambores a qual de acordo com suas dimensões foram extraídos seu peso e volume que comporta. Para o cálculo de volume utilizou-se a seguinte equação:

$$
\mathrm{V}=\pi \cdot r^{2} \cdot \mathrm{h}
$$

(Equação 1)

Em que:

$V=$ Volume do tambor, $\quad r=$ Raio do tambor $e$ $\mathrm{h}=$ altura do tambor.

Foram utilizados no total 9 (nove) coletores aos quais foram pesados individualmente e identificados com o tipo de resíduo nele a ser deposi- tados (Papel, papelão, vidro, metal, plástico, Politereftalato de etileno - Pet, matéria orgânica, alumínio e rejeito).

Realizou-se antes do processo de caracterização uma orientação geral com os funcionários da prefeitura que auxiliavam no processo sobre os tipos de resíduos e sua composição. Esta orientação é fundamental para uma destinação correta dos diferentes tipos de resíduos nos coletores.

Foram manipulados todos os tipos de resíduos onde os sacos de lixo fechados eram rasgados e segregados os diferentes tipos de resíduos que ali estivessem.

Para que não houvesse erros quanto à caracterização foram alocados bolsistas (Figura 7) junto aos recipientes coletores para auxiliarem e tirarem dúvidas referentes à qual o tipo de resíduo e qual composição os mesmos se caracterizavam.

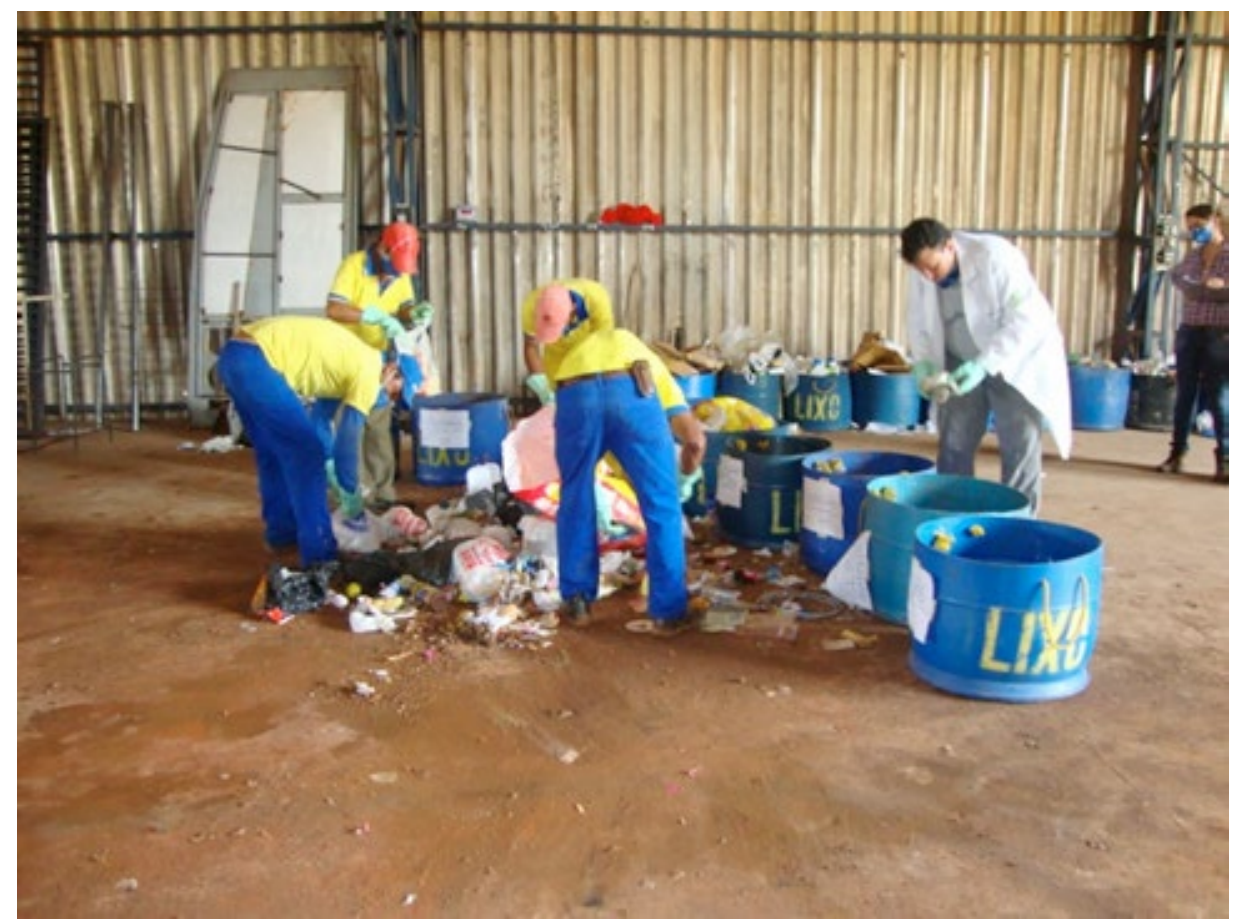

Figura7 - Segregação dos resíduos sólidos. Crédito da Imagem: Hygor Evangelista Siqueira 
À medida que os resíduos chegavam ao limite dos tambores era realizada a pesagem individual e subtraía o peso do tambor vazio e computava os resultados juntamente com o volume.

\section{RESULTADOS E DISCUSSÃO}

Analisando os resíduos sólidos gerado na Cidade de Nova Ponte (massa e volume) definidos nos levantamentos de dados realizados nos dias 08,10 e 12 de abril de 2013 foram computados a geração total semanal de $42.683 \mathrm{Kg}$. Segundo o IBGE (2010), o município contabiliza 10.991 habitantes na zona urbana, as quais contribuíram diretamente com esta geração.

A geração per capita no período analisado foi de 0,554 kg de resíduos sólidos por habitante, podendo ser ainda maior nos períodos de festas e eventos na região, uma vez que a cidade tem um grande atrativo turístico nos meses de dezembro e fevereiro.

Monteiro et al. (2001) apontaram a variação da geração de RSU per capita de acordo com o tamanho da cidade e sua população. Para uma cidade pequena é considerada uma população urbana até 30 mil habitantes, com uma geração per capita de $0,5 \mathrm{~kg} / \mathrm{hab} . / \mathrm{dia}$, estando assim aproximado da realidade de Nova Ponte no período analisado.

Com relação aos resultados das amostragens e da caracterização gravimétrica dos resíduos sólidos do município de Nova Ponte-MG verificou-se que durante os três dias de coleta foram caracterizados $876,3 \mathrm{~kg}$ e um volume total de $6,27 \mathrm{~m}^{3}$ de resíduos sólidos.

Na Tabela 1, são ilustrados os dados da composição gravimétrica dos resíduos sólidos urbanos da cidade de Nova Ponte - MG, no ano de 2013.

Tabela 1 - Composição Gravimétrica dos Resíduos Sólidos de Nova Ponte - MG

\begin{tabular}{|c|c|c|c|c|c|c|c|}
\hline \multirow{2}{*}{$\begin{array}{c}\text { Data } \\
\text { Material }\end{array}$} & \multicolumn{2}{|c|}{$\begin{array}{l}\text { 08-04-2013 } \\
\text { Segunda-feira }\end{array}$} & \multicolumn{2}{|c|}{$\begin{array}{l}\text { 10-04-2013 } \\
\text { Quarta-feira }\end{array}$} & \multicolumn{2}{|c|}{$\begin{array}{l}\text { 12-04-2013 } \\
\text { Sexta-feira }\end{array}$} & \multirow[b]{2}{*}{$\begin{array}{l}\text { Percentual (\%) } \\
\text { (massa) }\end{array}$} \\
\hline & $\begin{array}{c}\text { Massa } \\
(\mathbf{k g})\end{array}$ & Vol. $\left(\mathrm{m}^{3}\right)$ & Massa (kg) & $\begin{array}{l}\text { Vol. } \\
\left(\mathrm{m}^{3}\right)\end{array}$ & Massa (kg) & Vol. $\left(\mathrm{m}^{3}\right)$ & \\
\hline Papel & 7,288 & 0,058 & 8,95 & 0,12 & 12,25 & 0,06 & 3,25 \\
\hline Papelão & 12,46 & 0,272 & 15,25 & 0,41 & 21,05 & 0,418 & 5,56 \\
\hline Plástico & 31,9 & 0,53 & 21,45 & 0,48 & 25,3 & 0,504 & 8,98 \\
\hline Pet & 8,05 & 0,28 & 3,7 & 0,165 & 3,55 & 0,165 & 1,75 \\
\hline Vidro & 4,6 & 0,02 & 4,1 & 0,01 & 1,05 & 0,012 & 1,11 \\
\hline Alumínio & 1,25 & 0,05 & 1,1 & 0,044 & 0,35 & 0,022 & 0,31 \\
\hline Metal & 1,8 & 0,03 & 1,5 & 0,028 & 0,65 & 0,014 & 0,45 \\
\hline $\begin{array}{l}\text { Matéria } \\
\text { Orgânica }\end{array}$ & 117,5 & 0,26 & 124,45 & 0,36 & 113,3 & 0,3 & 40,54 \\
\hline Rejeitos & 159,7 & 0,67 & 79,15 & 0,55 & 94,55 & 0,44 & 38,05 \\
\hline TOTAL & 344,6 & 2,17 & 259,65 & 2,167 & 272,05 & 1,935 & 100 \\
\hline
\end{tabular}


Os resíduos orgânicos foram o que tiveram maior percentual (40,54\%) que é comum na maioria das cidades brasileiras. Estas altas concentrações de matéria orgânica se dão principalmente pela grande quantidade de alimentos que são desperdiçados diariamente em todas as cidades e que na maioria delas, estes resíduos não estão sendo aproveitado para o processo de compostagem, gerando assim grande volume a ser depositados nos aterros e lixões. Para Pereira Neto (2007) o desperdício de alimentos tem-se mostrado uma prática no Brasil, com taxa em torno de $64 \%$ para matéria orgânica disposta em aterros ou lixões.

Os rejeitos que são compostos por demais materiais de difícil classificação (trapos, couros, etc.;) e/ou que ainda não possa ser reciclado obteve $38,05 \%$ do total amostrado. Foi observada durante o estudo, uma quantidade significativa de roupas e sapatos em bom estado de uso durante os três dias de amostragem. Observa-se neste caso um aspecto cultural de alguns moradores, pois sendo inservíveis para eles estes resíduos gera- dos, poderiam ser doados e utilizados por outras pessoas mais carentes.

Foram gerados $15,85 \%$ de materiais recicláveis entre eles: papel $(3,25 \%)$, papelão $(5,56 \%)$, plástico $(8,98 \%)$, Pet $(1,75 \%)$, vidro $(1,11 \%)$, alumínio $(0,31 \%)$ e metais $(0,45 \%)$. Estes materiais não estão sendo destinados à reciclagem, gerando um grande desperdício econômico em relação à venda dos materiais e ainda social na geração de emprego e renda para os catadores que poderiam estar atuando na coleta seletiva no município.

Em um estudo realizado por Pereira Neto e Lelis (1999) no qual foi realizada a caracterização gravimétrica dos resíduos sólidos urbanos em 300 cidades de diferentes regiões do estado de Minas Gerais entre elas a região do Triângulo Mineiro e o Alto Paranaíba onde consecutivamente o município em estudo faz limite e está inserido. Pode observar na Tabela 2, resultados de percentuais de composição dos materiais presentes nos RSU semelhantes ao apresentado neste estudo.

Tabela 2 - Comparativo do percentual de materiais presentes nos Resíduos Sólidos Urbanos na região do Alto Paranaíba e Triângulo Mineiro e a do município de Nova Ponte - Minas Gerais.

\begin{tabular}{|c|c|c|c|}
\hline $\begin{array}{c}\text { Região/Cidade } \\
\text { Material }\end{array}$ & $\begin{array}{c}\text { Alto Paranaíba } \\
\text { (1999) }\end{array}$ & $\begin{array}{c}\text { Triângulo Mineiro } \\
\text { (1999) }\end{array}$ & $\begin{array}{c}\text { Nova Ponte } \\
\text { (2013) }\end{array}$ \\
\hline Papel (\%) & 3,3 & 2,2 & 3,25 \\
\hline Papelão(\%) & 6,9 & 4,8 & 5,56 \\
\hline Plástico Duro (\%) & 1,9 & 2,0 & \multirow{2}{*}{8,98} \\
\hline Plástico Filme (\%) & 5,5 & 4,8 & \\
\hline PET (\%) & 1,3 & 1,9 & 1,75 \\
\hline Vidro (\%) & 2,0 & 1,9 & 1,11 \\
\hline Alumínio (\%) & 0,4 & 0,5 & 0,31 \\
\hline Metais (\%) & 2,8 & 4,0 & 0,45 \\
\hline Mat. Orgânica (\%) & 67,1 & 66,8 & 40,54 \\
\hline Rejeitos (\%) & 8,8 & 11,1 & 38,05 \\
\hline TOTAL (\%) & 100 & 100 & 100 \\
\hline
\end{tabular}

Fonte: LESA/UFV (Modificado e adaptado de PEREIRA NETO e LELIS, 1999) 
Os valores de Matéria Orgânica e de Rejeito foram o que mais se diferenciaram entre os resíduos caracterizados. Esta diferença pode estar associada ao tipo de método de classificação de rejeitos, que em nosso estudo, consideramos rejeito além ainda dos demais (papel higiênico, fraldas, absorventes, etc.;), a sobra do pátio com resíduos misturados e já contaminados que já não poderia mais ser separados e ainda resíduos de difícil classificação.

\subsection{Balanço de massa e volumétrico}

A Tabela 3 apresenta os resultados e o percentual dos resíduos sólidos caracterizados no estudo gravimétrico, o que tornou possível realizar o balanço de massa e volumétrico, além ainda de resultar na quantificação do potencial de reintegração ambiental dos resíduos sólidos urbanos.

Para obter o potencial de reintegração, foram considerados os materiais potencialmente re- cicláveis, descontando-se possíveis rejeitos (ou material de baixa qualidade) que não são absorvidos pela indústria e os materiais potencialmente compostáveis, dos quais são descontadas as perdas ocorridas durante o processo de compostagem (vapor d'água, volatilização de gases) e os rejeitos do peneiramento do composto, tratandose, em sua maioria, de fragmentos de materiais inertes que se encontravam misturados à matéria orgânica.

Com estes dados disponíveis, estimou-se haver $15 \%$ (típico) de rejeito no processo de triagem e 12\% (típico) na compostagem, além da perda natural no processo de compostagem que é em média de $40 \%$.

A Figura 8 apresenta o balanço de massa dos RSU gerados no município de Nova Ponte - MG e que durante o estudo resultou em uma massa semanal de $42683 \mathrm{Kg}$ e um volume semanal de $305,5 \mathrm{~m}^{3}$.

Tabela 3 - Resultados dos dados de massa e volume dos Resíduos Sólidos Urbanos de Nova Ponte - MG.

\begin{tabular}{|c|c|c|c|c|c|}
\hline Material & $\begin{array}{c}\text { Massa Total } \\
\text { Amostra } \\
(\mathbf{k g})\end{array}$ & $\begin{array}{l}\text { Volume } \\
\text { Total } \\
\text { Amostra } \\
\left(\mathbf{m}^{3}\right)\end{array}$ & $\begin{array}{c}\text { Percentual } \\
\text { Amostra Massa } \\
\text { (\%) }\end{array}$ & $\begin{array}{c}\text { Massa } \\
\text { Total Semanal } \\
\text { (kg) }\end{array}$ & $\begin{array}{c}\text { Volume } \\
\text { Total Semanal } \\
\left(\mathbf{m}^{3}\right)\end{array}$ \\
\hline Vidros ${ }^{\circledR}$ & 9,75 & 0,042 & 1,11 & 473,78 & 2,04 \\
\hline Papel $®$ & \multirow{2}{*}{77,25} & \multirow{2}{*}{1,34} & \multirow{2}{*}{8,81} & \multirow{2}{*}{3760,37} & \multirow{2}{*}{65,22} \\
\hline Papelão $®$ & & & & & \\
\hline Alumínio® & 2,7 & 0,12 & 0,31 & 132,32 & 5,88 \\
\hline $\begin{array}{l}\text { Metal } ® \text {, latas } ® \text {, } \\
\text { ferrosos } ₫\end{array}$ & 3,95 & 0,07 & 0,45 & 192,07 & 3,4 \\
\hline Pet $®$ & 15,3 & 0,61 & 1,75 & 746,95 & 29,78 \\
\hline Plástico ${ }^{\circledR}$ & 78,65 & 1,51 & 8,96 & 3832,93 & 73,58 \\
\hline Matéria Orgânica & 355,3 & 0,92 & 40,46 & 17303,69 & 44,8 \\
\hline Rejeito & 333,5 & 1,66 & 37,97 & 16240,89 & 80,83 \\
\hline TOTAL & 876,3 & 6,272 & 100 & 42683,0 & 305,5 \\
\hline
\end{tabular}

(®) Recicláveis 


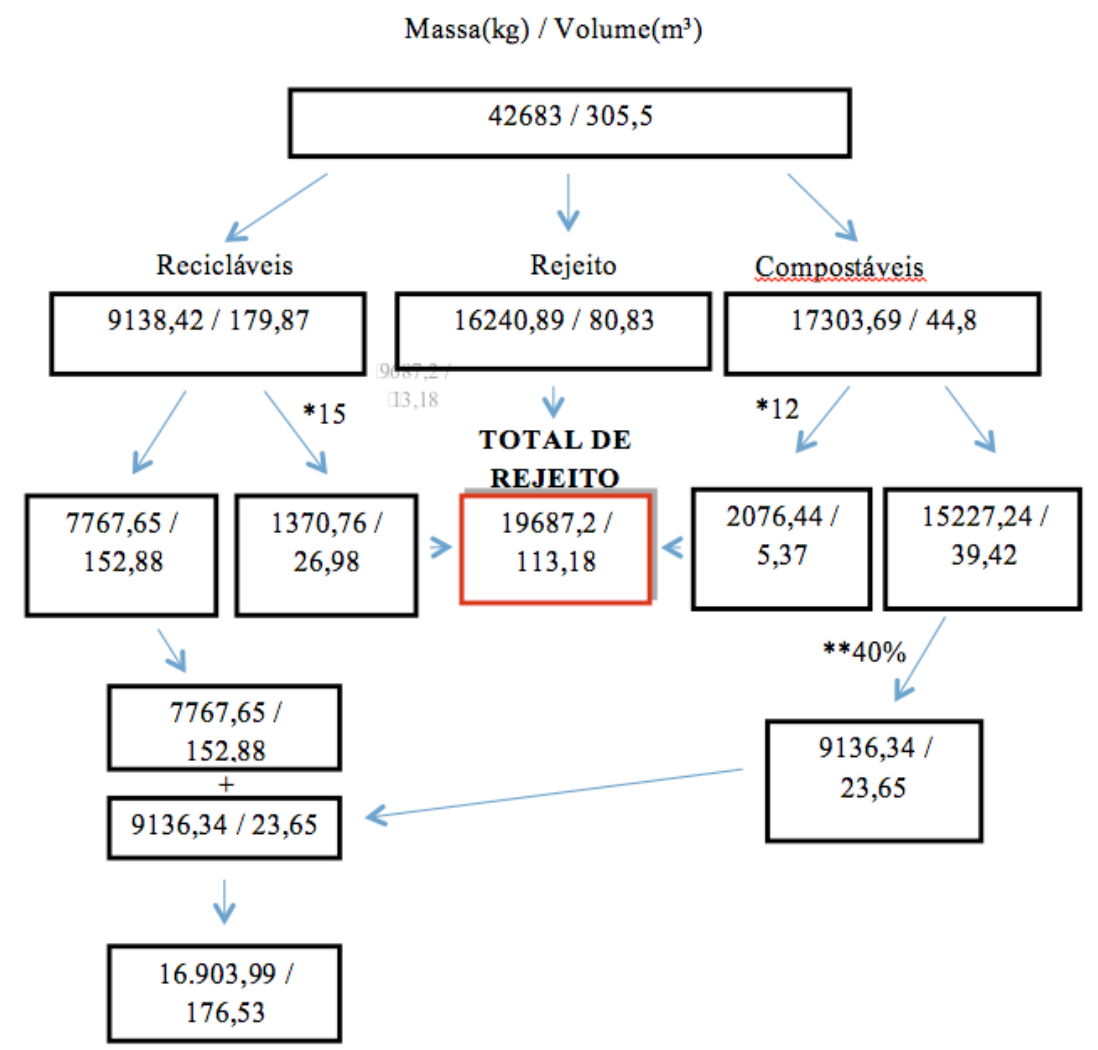

Figura 8 - Balanço de massa dos RSUs gerados no município de Nova Ponte.

Notas: "Valores estimados, baseados em resultados usualmente encontrados em sistemas de triagem e compostagem de lixo, quando bem operados. * Considerando a compostagem da matéria orgânica fresca.

Ao se analisar o balanço de massa dos RSU, percebe-se que há um grande potencial de reintegração ambiental, econômica e social, $(39,40 \%)$ fazendo com que haja a necessidade do município adotar um sistema que priorize a reciclagem e a compostagem desses resíduos, uma vez que esta, contribuirá com os aspectos sociais, ambientais e ainda poderá gerar receita para o município.

Dos $42683 \mathrm{~kg}$ de resíduos sólidos gerados, 46,12\% é caracterizado como rejeito que é composto por parcela do lixo sem potencial de reutilização juntamente com os rejeitos do processo de compostagem e materiais inertes que não apresentem qualificação para a venda. $O$ destino ambientalmente correto para este material é o aterro sanitário. Esta quantificação é muito importante para se definir estudos para dimensionamento de aterro sanitário para o município, uma vez que são estes resíduos que deverão ser dispostos no aterro sanitário.

Do total de resíduos caracterizado pela matéria orgânica $17303,69 \mathrm{~kg}$ considerando a perdas naturais no processo e ainda o rejeito no processo, 9136,34 kg resultam em composto orgânico, gerando assim uma grande economia de área caso fosse destinado ao aterro sanitário diretamente e diariamente. As perdas no processo de compostagem que em média corresponde a $40 \%$ se dão principalmente pela volatilização de gases e vapor d'água. 


\section{CONCLUSÕES}

O município possui uma geração média per capita de $0,555 \mathrm{~kg} \cdot$ hab.dia. $^{-1}$.

A geração de RSU no município totalizou uma massa semanal de $42683 \mathrm{~kg}$ e um volume semanal de 305,5 $\mathrm{m}^{3}$ de resíduos sólidos.

Da geração total semanal $7767,65 \mathrm{~kg}$ e um volume semanal de $152,88 \mathrm{~m}^{3}$ são resíduos que potencialmente recicláveis.

A matéria orgânica presente correspondeu à geração total de $17303,69 \mathrm{~kg}$ e 44,8 $\mathrm{m}^{3}$ que após o processo tende a serem compostos orgânico $9136,34 \mathrm{~kg}$ e $23,65 \mathrm{~m}^{3}$.

Do total de RSU gerados $19687,2 \mathrm{~kg}$ e 113,18 $\mathrm{m}^{3}$ são considerados rejeito sendo este tendo que ser destinado impreterivelmente ao aterro sanitário.

\section{REFERÊNCIAS}

ABNT - ASSOCIAÇÃO BRASILEIRA DE NORMAS TÉCNICAS. NBR 10.007: Amostragem de resíduos sólidos: Rio de Janeiro, 2004. 21 p.

ALCÂNTARA, A. J. O. Composição gravimétrica dos resíduos sólidos urbanos e caracterização química do solo da área de disposição final do município de Cáceres-MT. 2010. 88f. Dissertação (Mestrado em Ciências Ambientais), Universidade do Estado de Mato Grosso, Cáceres, 2010.

BARROS, R. T. V., MÖLLER, L. M. Limpeza Pública. In: BARROS, R. T. $V$, et al. Manual de saneamento e proteção ambiental para os municípios. v.2. Belo Horizonte: Escola de Engenharia da UFMG, 1995. cap. 7, p. 181-208.
BIDONE, F. R. A; POVINELLI, J. Conceitos básicos de resíduos sólidos. São Carlos: EESC/USP, 1999. 120 p.

BRASIL. Lei n 12305 de 02 de agosto de 2010. Institui a Política Nacional de Resíduos Sólidos; altera a Lei no 9.605, de 12 de fevereiro de 1998; e dá outras providências. Ministério do Meio Ambiente. Brasília, DF, 2010. Disponível em: <http:/www.mma. gov.br/port/conama/legiabre.cfm?codlegi=636>. Acesso em: 10 set.2013.

IBGE - Instituto Brasileiro de Geografia e Estatística. Censo Nacional. Rio de Janeiro: IBGE, 2010.

MATTEI, G.; ESCOSTEGUY, P. A. V. Composição gravimétrica de resíduos sólidos aterrados. Revista de Engenharia Sanitária e Ambiental, Rio de Janeiro, v. 12, n. 3, p. 247-251, 2007.

MONTEIRO, J. H. P.; FIGUEREDO, C. E. M.; MAGALHÃES, A. F.; MELO, M. A. F.; BRITO, J. C. X.; ALMEIDA, T. P. F.; MANSUR, G. L. Manual de gerenciamento integrado de resíduos sólidos. Rio de Janeiro: IBAM, 2001. 200p.

PEREIRA NETO, J.T.; Lelis, M. P. N. Variação da Composição Gravimétrica e Potencial de Reintegração Ambiental dos Resíduos Sólidos Urbanos por região Fisiográfica do Estado de Minas Gerais. In: Congresso Brasileiro de Engenharia Sanitária e Ambiental; 20, 1999, Rio de Janeiro. Anais...Rio de Janeiro: ABES, 1999. p.1709-1716.

PEREIRA NETO, J. T.; Gerenciamento do lixo urbano: aspectos técnicos e operacionais. Viçosa: UFV, 2007.129 p.

RIBEIRO. L. M. M., Avaliação quantitativa da segregação de resíduos sólidos recicláveis no município de Canoas - RS. In: Congresso Brasileiro de Engenharia Sanitária e Ambiental; 24, 2007, Belo Horizonte. Anais... Belo Horizonte: ABES, 2007. p.11-17.

SISINNO, C. L. S. Avaliação da contaminação e poluição ambiental na área de influência do aterro controlado do Morro do Céu, Niterói, Brasil. Caderno de Saúde Pública, Rio de Janeiro, v.12, n.4, p. 515-523,1996. 